\title{
A confusão das fronteiras
}

1 crescente ampliação do uso de tecnologias de comunicação no ambiente de trabal ho apresenta-se como um fenômeno ambíguo. De um lado, agiliza trocas de informação e contribui para a construção de redes de relacionamento. De outro, enfraquece as fronteiras entre trabal ho e vida pessoal. 0 desafio das empresas é o de capital izar o efeito dessas tecnologias sem perder de vista metas de eficiência e produtividade.

\section{por Julio Daio Borges Digestivo Cultural}

As novas tecnologias de informação e comunicação, afora suas alardeadas vantagens para o mundo corporativo, trazem paradoxos inusitados quando analisadas à luz da relação entre empregadores e empregados. Enquanto os primeiros exigem mais horas trabalhadas, maior concentração e alta produtividade, os empregados, passando cada vez mais tempo no trabalho, procuram brechas para respirar em intervalos, ligações de celular e comunicação eletrônica em geral.

$\mathrm{N}$ a medida em que a Internet e a comunicação interpessoal parecem ter se associado hoje de forma inseparável, os empregadores estudam o comportamento de seus 
funcionários eadotam métricas para monitorar a eficiência mesmo no meio da dispersão. Já empregados, sentindo-se vigiados, e às vezes sentido sua privacidade ameaçada pela invasão, compensam a situação fazendo uso de "torpedos", mensageiros instantâneos esites de relacionamento. Qual o impacto dessas tecnologias no ambiente de trabalho? E qual a melhor forma de tirar proveito - sempre em benefício da empresa - dessa nova realidade?

de telefonia, mas, como conseqüência, interferiu nas relações de trabal ho. Desde a decoração das chamadas "baias" até a personalização do sistema operacional Windows e da sua área de trabalho (leia-se: tela do computador), a psicologia (e o RH) explica(m) que sempre foi importante - para que o empregado se sentisse mais "em casa" - personalizar, ao máximo, o entorno.

Porta-retratos, fotos de família, pequenos ícones em cima do monitor, canetas ou lápis e até canecas de café, chá ou água - tudo era permitido pelos empregadores a fim de que, "familiarizada" com seu espaço, a pessoa pudesse se sentir mais à vontade e, conseqüentemente, produzir mais. Acontece que, com a chegada das novas tecnologias, que atingem plenamente 0 indivíduo - sem ter de passar pelo crivo de recepcionistas, ramais e

Paradoxos da tecnol ogia. Ao mesmo tempo em que os empregadores acusam os empregados de produzirem menos, depois da era da comunicação interpessoal, e, por esse motivo, exigem mais horas trabal hadas (para compensar a perda de produtividade), os empregados queixam-se das cada vez mais longas jornadas de trabalho impostas pelos patrões. Como conseqüência, burlam as horas a mais com diversão eletrônica, conversas estritamente pessoais e atividades extracurriculares no ambiente de trabal ho.

Os empregadores querem, como na indústria, eficiência total - mas os empregados, reagindo à automatização e à desumanização das funções (cada vez mais fragmentadas), buscam novas estratégias para tornar 0 ar do escritório mais respirável. Os empregadores proíbem, por exemplo, o uso do MSN, o mensageiro eletrônico da Microsoft; os empregados, em resposta, recebem mais chamadas pelo celular (e tem de se ausentar mais de seus postos). Do mesmo jeito, os empregadores proíbem o webmail (Hotmail, Yahoo! e afins); ato contínuo, os empregados descobrem os "recadinhos" do Orkut (no Brasil, o mais popular site de relacionamentos).

A era da comunicação pessoa-a-pessoa, a partir dos anos 1990 no Brasil, trouxe muitos lucros para as empresas secretárias - , a personalização do local físico se estendeu para um uso generalizado das novas tecnologias de comunicação para tornar 0 ambiente de trabalho (quase) uma extensão da própria casa. Vejamos alguns exemplos.

J anelas virtuais. 0 primeiro deles é o email. Quem não tem problemas, desde o office-boy até o executivo do mais al to escalão, em separar a correspondência el etrônica pessoal da de trabalho? Das mensagens dos amigos às dos chefes; das "correntes" em família às atas de reunião; das promoções e newsletters relacionadas às horas de lazer aos lembretes para as listas de pendências. Mais dia, menos dia, o e mail corporativo acaba se misturando com assuntos que indubitavelmente não dizem respeito a trabalho - afinal, cartões de visita (e de business) são distribuídos também durantes os finais de semana e em ocasiões em queo contato nem sempre é de negócios.

$\mathrm{Na}$ outra ponta, as empresas tentam se assegurar de que o limite de mensagens el etrônicas pessoais está dentro do tolerável - em seus servidores. Todo mundo sabe que o pessoal de TI (tecnologia da informação, vulgo "informática") tem acesso a tudo o que se envia e se recebe (embora isso não iniba a comunicação estritamente pessoal); tendo, 
inclusive, autorização para notificar, a quem interessar possa, sobre qualquer conteúdo impróprio - incorrendo o usuário, às vezes, em severas penalidades.

Muita gente pode até dizer que essa discussão não é novidade, pois muitas dessas questões já se colocavam antes, na era do telefone fixo. De fato, com a democratização dos ramais, por exemplo, ficava cada vez mais difícil impor limites à conversação pessoal - sem ser brusco, deselegante ou mesmo deseducado. Algumas empresas tentaram equacionar o problema introduzindo um código para ligações de trabalho e outro para as pessoais - sendo que cada funcionário pagava, no final do mês, por suas ligações sem relação com o escritório. E mesmo que isso não fosse cobrado, ou descontado do salário, era uma maneira de saber quanto tempo se gastava com uma coisa e com outra.

O telefone celular, porém, prejudicou a eficiência desse sistema. A partir de então, ficava praticamente impossível impedir que alguém recebesse uma ligação, em ambiente de trabalho, sem ser autoritário e obrigar o dono a desligar 0 aparelho. Fora isso, a ligação vinha diretamente, sem passar por mais ninguém da empresa; e sem contar que, mesmo na eventualidade de não possuir um ramal próprio, o celular estava lá, como uma porta aberta para a rua.

Quase junto com os e-mails, e a Internet, vieram os mensageiros instantâneos: softwares que permitem contato direto, via chat (conversação), com alguém que esteja on-line e na lista de "contatos". Como um aparelho de telefone do tipo "conexão direta" (N extel), ou um "rádio", que não "desliga" nunca, só que na tela do computador e por escrito (o uso de câmera e de som, embora exista, é mais domiciliar).

Muitos, no mundo corporativo hoje, inclusive, relatam o impacto dos mensageiros el etrônicos sobre os telefones celulares e vice-versa. Apesar de um MSN (o mensageiro da Microsoft), por exemplo, ter várias aplicações profissionais - na transmissão de arquivos, em pequenos contatos que dispensam telefone (DDD ou DDI idem), até em reuniões não presenciais - , os IMS (instant messengers, em inglês) acabam dando vazão a comunicações extremamente pessoais. É comum que sirvam a intervalos em que se quer jogar, literalmente, conversa fora; também para combinar programas depois do expediente; e ainda para cultivar relacionamentos ou manter amizades à distância.

Dependendo da configuração, os mensageiros eletrônicos abrem suas janelas logo que o computador é ligado ou, então, quando é conectado à Internet. Ou seja: antes de começar, 0 adepto do MSN já pode ser interrompido para uma conversa; antes mesmo de checar o e-mail, pode querer passar um recado para a namorada; ou, mal deu bom-dia a seus colegas, já está sendo interrompido pelo histórico de conversações não realizadas enquanto ele estava "fora do ar".

Inimigos poderosos. Empresas que encontraram no mensageiro instantâneo um inimigo e tentaram proibi-lo toparam, na seqüência, com seu "aliado" mais próximo: 0 telefone celular. Quem fala menos no MSN - as estatísticas

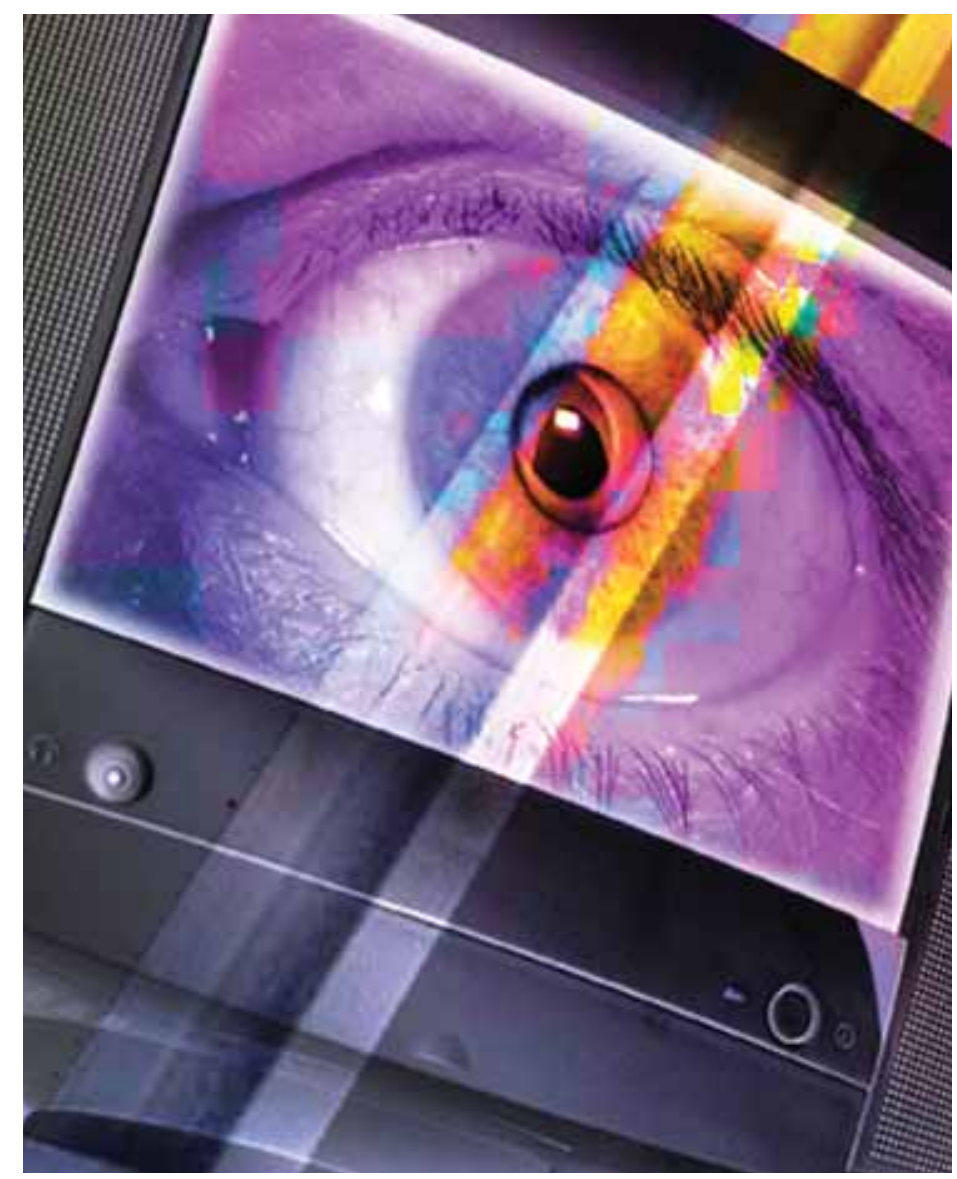


estão mostrando - fala depois, mais, no celular; levanta mais vezes da cadeira; sai mais vezes do que o normal da sala. Qual o meio-termo? No momento, ainda não há. Talvez acompanhar o log (registro) de conversações do referido mensageiro instantâneo; talvez instituir que as conversas serão todas gravadas - o que levaria os adeptos mais crônicos a ponderar quando um bate-papo mereceria (ou não) estar no servidor da empresa, ao al cance de um webmaster, do administrador da rede ou do próprio helpdesk.

$M$ ais raros no Brasil, mas muito freqüentes, por exemplo, nos Estados Unidos são os blogs pessoais em ambientes de trabal ho. Blogs corporativos, claro, podem ter uma aplicação inteligente e, na maioria dos casos, devem ser estimulados. Blogs pessoais, no entanto, podem ser a simples manifestação do "eu", um fator de dispersão e até - nos EUA já aconteceu - um complicador nas relações profissionais. o site de relacionamentos do Google. A experiência de fazer mídia, atrair uma audiência eaté mobilizar gente em torno de al guma causa não ocorreu em blogs brasileiros ainda. Os internautas do Brasil estão tendo a experiência de "perda" da privacidade, dos "golpes" e dos chamados "abusos" on-line, agora via Orkut - onde se pode hospedar gratuitamente uma página, preenchêla com dados pessoais (e/ou profissionais), adicionar fotos, (re)encontrar amigos, deixar recados ou "testemunhos", einscrever-se em comunidades quevão ao encontro da própria personalidade. $E$, apesar de existirem outros sites de relacionamento mais apropriados ao mundo corporativo - como, por exemplo, o Linkedln «ttp://www.linkedin.com/> -, os brasileiros estão transformando o Orkut em uma ferramenta de trabal ho, a ponto de profissionais de marketing e comunicação, como André Telles, estarem lançando livros sobre o fenômeno.

\section{Se por um lado as tecnologias de comuni cação} "roubam" tempo e produtividade das

\section{empresas, consumindo a atenção e a energia}

\section{de seus funcionários, por outro lado, estão}

\section{disponi bilizando dados que valem muito, até}

\section{em termos de pesquisa e desenvolvimento.}

Uso inteligente. Telles introduz, basicamente, o conceito de Orkut corporativo, e elenca suas vantagens para o executivo e para a empresa. N um exercício de extrapolação, afirma que a página no Orkut pode servir como instrumento de marketing pessoal, onde cada um projeta a imagem mais adequada - estruturando, inclusive, sua lista de contatos (ou "amigos") em torno de pessoaschave que possam futuramente,

M esmo o Google, com toda a sua vanguarda e aparente liberalidade no trato com funcionários, já dispensou pessoas por causa de críticas à empresa, justamente em blogs pessoais. Estudiosos da nova ferramenta de publicação em universidades acreditam que o blog pessoal pode dar vazão a uma criatividade "extra", sufocada no ambiente de trabalho. Isso poderia ser verdade? Microsoft, Sun, HP e outras empresas do Vale do Silício preferem ver seus executivos "blogando" na página da empresa e extravasando suas críticas de maneira extra-oficial a correr o risco de ter uma crise por falta de comunicação.

No Brasil, é provável que o boom dos blogs pessoais esteja sendo eclipsado pelo boom de brasileiros no Orkut, quem sabe, alavancar sua carreira no trabal ho.

Do outro lado do balcão, profissionais de RH - exagero de Telles ou não - estão comparando as informações dessas páginas com as apresentadas nos currículos de candidatos em processo de seleção. Inscrever-se em comunidades como "eu paquero a secretária" ou "meu chefe não vale nada", portanto, nem pensar. Será mesmo? Telles diz que, à exceção desses disparates, as comunidades podem servir de fato ao marketing de segmentação, à subseqüente diferenciação de produto, pois é possível traçar um perfil psicológico - e gratuitamente, sem gastar com pesquisa (ainda que muitas dessas informações não sejam inteiramente confiáveis). 


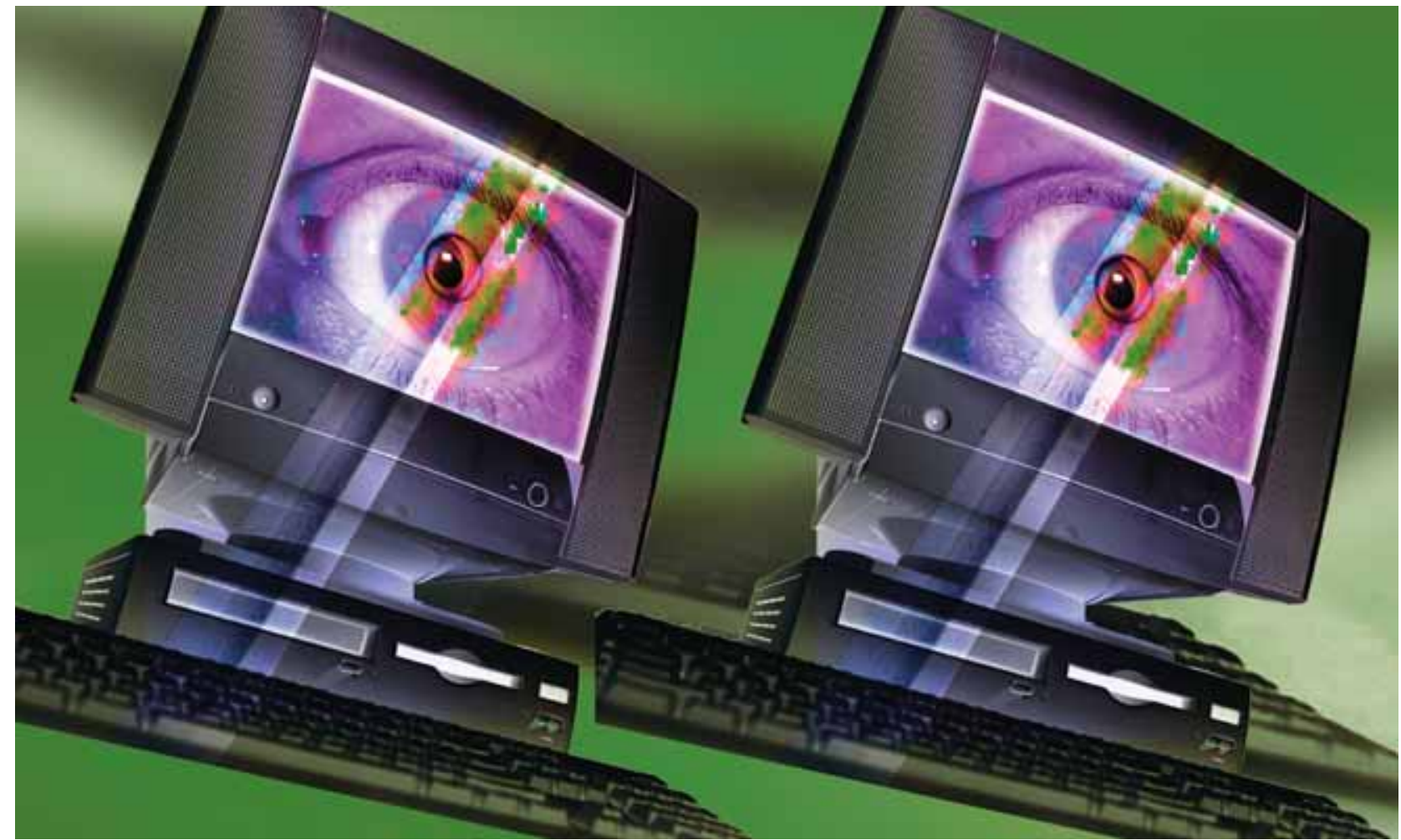

Comunidades no Orkut e blogs em geral têm, ainda, sido usados em ações de marketing de relacionamento. No Orkut, por exemplo, numa comunidade específica, existe a possibilidade de "agendar um evento" e convocar seus membros (algumas delas têm dezenas de milhares de inscritos). André Telles vai além e diz que blogs e "Orkuts" serão o futuro dos SACs (serviços de atendimento ao consumidor), onde as reclamações podem ser colhidas on-line (por exemplo, nas comunidades do tipo "eu odeio..."), enquanto as satisfações podem ser dadas, imediatamente, ao consumidor.

E não só Telles acredita que a inovação também pode vir daí - alternativas de produtos e/ou serviços, testadas e aprovadas por dezenas, centenas, às vezes, milhares de pessoas que, de uns tempos pra cá, estão externando seus desejos no espaço público (virtual). John Battelle, autor do livro que conta a história do Google, afirma que manifestações desse tipo, em blogs ou correlatos, vieram para ficar - afinal, como ele diz, para o consumidor final é muito mais interessante do que reclamar na frente da televisão.
A conclusão é que as novas ferramentas de comunicação são facas de dois gumes no mundo corporativo. Se, por um lado, "roubam" tempo e produtividade das empresas, consumindo a atenção ea energia de seus funcionários, por outro lado estão disponibilizando dados que valem muito, até em termos de pesquisa e desenvolvimento, e de uma maneira espontânea, sem custos diretos. Será que, no fim, o preço de se conhecer cada consumidor na sua intimidade é o de ter funcionários mais distraídos, acentuadamente dispersos e, algumas vezes, dedicados a atividades sem nenhuma conexão com o trabalho? É por razões como essas que o Google - mais uma vez - permite que cada funcionário seu dedique $20 \%$ do tempo no escritório a ter idéias e a desenvolver projetos que não têm necessariamente a ver com as outras horas trabal hadas. 0 Google acredita que isso dá retorno.

\section{Julio Daio Borges}

Editor do Digestivo Cultural

E-mail: j.d.borges@digestivocultural.com 